\title{
O LÓCUS ENUNCIATIVO DO SUJEITO SUBALTERNO: FALA E EMUDECIMENTO
}

\author{
Tayane Rogeria Lino* \\ Universidade Federal de Minas Gerais
}

\begin{abstract}
Resumo: O artigo busca investigar a fala/silêncio dos sujeitos, tendo como objetivo estabelecer uma discussão em torno do complexo debate acerca do lócus enunciativo do sujeito subalterno na vida social contemporânea, principalmente, no campo científico. Foram tomadas como foco deste trabalho as contribuições da teórica Gayatri Chakravorty Spivak (2010) no texto "Pode o subalterno falar?", onde a autora afirma que os subalternos são aqueles que não participam, ou participam de modo muito limitado, sendo sujeitos mudos pelo imperialismo cultural e pela violência epistemológica. Não há um consenso sobre o cunho propositivo ou sobre a resignação nas teorizações de Spivak (2010). Inúmeras críticas são feitas ao pensamento da intelectual. Se por um lado alguns vão nomear as proposições de Gayatri como uma teórica que não propõe nenhuma saída da condição de inferiorização dos subalternos. Outros vão pontuar que ela assume uma postura firme e corajosa ao afirmar que a responsabilidade pelo combate à subalternidade é papel dos intelectuais. O ponto central deste ensaio é a busca por estruturas teóricas, textuais, sociais e políticas que possam propiciar a emergência de vozes que foram silenciadas por forças políticas imperialistas. Para tanto contou-se como aporte teórico os Estudos Subalternos sul-asiáticos e Pós-coloniais questionou-se sobre estes novos sujeitos da produção científica e sua enunciação. Esse campo teórico apresentou-se como uma importante contribuição para o campo científico, pois, traz o "outro" para a cena, o não falante, o silenciado, o que sempre ocupou o lugar de sujeito na ciência e, poucas vezes, o de sujeito da ciência.
\end{abstract}

Palavras-chave: Subalternidade. Enunciação. Subalterno. Estudos Subalternos.

Originário do latim subalternus, o termo subalterno, ganha grande circulação a partir das proposições do cientista político Antônio Gramsci (GRAMSCI, 2002; FIGUEIREDO, 2010; SIMIONATTO, 2010). Muitos conceitos desenvolvidos e elaborados por Gramsci caíram no uso popular e científico na atualidade (ROIO, 2007). O que não foi diferente com a ideia de subalterno.

Galgado no século XX, as primeiras noções sobre o termo vão aparecer nos seus

EY NC ND Esta obra está licenciada sob uma Licença Creative Commons.

\footnotetext{
* Possui graduação em Psicologia pela Universidade Federal de Minas Gerais (2011) e mestrado em Psicologia pela Universidade Federal de Minas Gerais (2014). Atualmente é vice-coordenadora do Instituto Mineiro de Saúde mental e Social - Instituto ALBAM, integra o colegiado gestor do núcleo BH da Associação Brasileira de Psicologia Social. E-mail: tayanelino@gmail.com.
} 
escritos gramisciano pré-carcerários, sendo empregado para referir-se inicialmente aos que deviam se submeter a outros "no contexto da hierarquia militar" (SIMIONATTO, 2010, p. 35). Já nos primeiros volumes dos Cadernos do Cárcere, o termo "subalterno" é apresentado, em vários momentos, associado ao proletário. Em seus estudos e investigações da classe operária, com frequência, a classe subalterna foi abordada como sinônimo de classe operária. É, no entanto, no texto intitulado Nos Confins de História, que compõe o sexto volume dos Cadernos do Cárcere, que Gramsci da uma nova roupagem ao termo ampliando largamente o seu significado (GRAMSCI, 2007; SIMIONATTO, 2010; NEVES, 2010). O termo classe subalterna passa a ser usado com a finalidade de se referir a grupos que estão fora da estrutura estabelecida de representação política (NEVES, 2010).Assim, o termo passou a se referir a qualquer pessoa ou grupo de categoria inferior, seja pela raça, gênero, classe, orientação sexual, etnia ou religião.

Neste sentido o alargamento do conceito de subalternidade, no pensamento de Gramsci, tenta recuperar os processos de expropriação a que os subalternos foram submetidos (PELÚCIO, 2012). Em consonância com este pensamento Simionatto (2010) afirma que para a compreensão da proposta gramsciana, é necessário tratar as classes subalternas a partir da (re)construção dos processos de dominação presentes na sociedade moderna, avaliar os nexos de legitimidade que eles produzem, desvendando "as operações político-culturais da hegemonia que escondem, suprimem, cancelam ou marginalizam a história dos subalternos" (BUTTIGIEG apud SIMIONATTO, 2010, p. 36). Para Gramsci (2002) a superação da condição de subalternidade exige uma vitória permanente sobre as classes dominantes, requer a construção de outros modos de ser e pensar, outra concepção de economia, política, ciência, enfim, de mundo. Trocando em miúdos, seria identificar o potencial contra hegemônico e "tornar as classes subalternas capazes de produzir uma contra hegemonia" (SIMIONATTO, 2010, p. 38).

O que vemos hoje é que o significado exato do termo, no uso filosófico e crítico atual, é contestado. Não há um consenso em torno de como se nomeia o outro como subalterno. Mas há um certo acordo quanto a sua finalidade, a dominação de sujeitos e grupos em detrimento da supervalorização de outros. Alguns pensadores utilizam o conceito em um sentido mais geral para se referir a grupos marginalizados, às classes menos abastadas, enfim, a pessoas e grupos sem agência ou possibilidade de representação por seus status sociais. Outros usam o conceito em um sentido mais específico e localizado cultural e historicamente. 
Foi a partir das proposições de Gramsci (2002) no texto Nos confins da história que teóricos como Eduard Said, Sturart Hall, Ranajit Guha e Gayatri Spivak, entre outros, começam, nos anos de 1970, a "trabalhar sobre o conceito e a história dos subalternos" (NEVES, 2010, p. 62). Estes pensadores passam a teorizar sobre o termo "subalterno" e as relações de subalternidade, principalmente, na sociedade indiana, introduzindo o que hoje conhecemos como "Estudos Subalternos Sul-asiáticos" o que reinaugura o uso do conceito subalterno.

Nesta corrente, os subalternos são vistos como grupos marginalizados, com ausência de voz ou representatividade, em decorrência de seus status sociais. O termo começou a ser usado como referência para povos colonizados no sul-asiático. O grupo de teóricos enunciam estes sujeitos como subalternos - vale ressaltar que eles são teóricos de origem indiana - e se debruçam em um esforço teórico político que possibilite um novo ponto de vista na história dos locais dominados que apenas era apresentada na perspectiva dos colonizadores. Neste pensamento, a subalternidade se trata de, segundo Figueiredo (2009, p. 20), "um atributo geral relacionado à subordinação da sociedade, em termos de classe, casta, idade, gênero e trabalho". É fornecida uma nova perspectiva sobre a história do lugar colonizado a partir da perspectiva do colonizado, ao invés da perspectiva de poder hegemônico.

Para Ranajit Guha (1982) o subalterno é idealizado como alguém que carece de poder e de autorrepresentação, a ele é negado todo e qualquer reconhecimento de sujeito da história. Não há, nesta definição, a construção de uma história própria e singular, o projeto de sociedade e de futuro são restritos aos subalternos (FIGUEIREDO, 2010). O subalterno, nesta perspectiva, é um não, um irregistrável, incapaz de agir como sujeito da própria história, um ausente.

Já, Homi Bhabha (2005), enfatiza a importância da compreensão das relações sociais como relações de poder em sua definição dos "subalternos". Percebe-os como grupos minoritários, cuja presença foi fundamental para a auto definição do grupo majoritário. Os grupos sociais subalternos, para este autor, têm um potencial transformado, estando em posição para subverter a autoridade de quem tem o poder hegemônico.

Para Gayatri Spivak ${ }^{1}$ (2004) o uso do termo subalterno não é apenas um sinônimo para oprimidos ou para os "outros”. Os subalternos são sujeitos e grupos sem autonomia,

\footnotetext{
${ }^{1}$ Gayatri Spivak é uma teórica crítica de origem indiana, cujo trabalho tem sido particularmente influente no campo do pós-colonialismo. Entre seus interesses de pesquisa estão o feminismo, o marxismo, a desconstrução e a globalização. Desconstrucionista, Gayatri Spivak sofreu grande influência do pensamento de Jacques Derrida. A autora questiona o colonialismo e a forma como este sistema condicionou a forma de pensar sobre literatura,
} 
submetido a outro grupo social, não possuindo posição própria legítima e se afastando de uma posição hegemônica, "os que não conseguem lugar em um contexto globalizante, capitalista, totalitário e excludente" (FIGUEIREDO, 2010, p. 85). Assim o subalterno é aquele que tem a fala impedida de reconhecimento e consequentemente escuta.

Sobre a influência do pensamento gramisciano, Spivak, em recente entrevista a Gago e Obarrio (2013), afirma que "a agrada a palavra 'subalterno' por uma razão. É situacional” (S/N, tradução minha). Ao contrário de várias críticas (MAGGIO, 2007; FIGUEIREDO, 2010; PELÚCIO, 2012) ao caráter estanque de sua teoria, Spivak afirma o caráter de mobilidade do termo, o historiciza e contribui para o não essencialismo dos fenômenos sociais. A subalternidade aqui não é vista como um caráter imutável, mas como resultado de relações de poder em que todos se encontram ora em lugares de "colonizador" ora em uma posição "subalterna". Vale ressaltar que alguns sujeitos encontram-se, em múltiplas esferas sociais, em uma posição subalterna, em outras palavras, há sujeitos que transitam pouco entre estas posições.

Em sua proposição teórica, o subalterno é aquele que tem limitado ou nenhum acesso às instâncias de fala, resultado de um imperialismo cultural. Gayatri Spivak sugere que ao subalterno é negado o acesso a ambas as formas miméticas e política de representação. A autora afirma que o "subalterno" descreve "as camadas inferiores da sociedade constituída por modos específicos de exclusão de mercados, político-legal de representação, e a possibilidade de adesão plena em estratos sociais dominantes" (SPIVAK, 1999, p. XX, tradução nossa).

Os subalternos são, nas proposições de Spivak, todos aqueles que não participam, ou que participam de modo muito limitado. São sujeitos mudos pelo imperialismo cultural e pela violência epistemológica, sendo a mulher subalterna, nesse sentido, duplamente colocada na sombra (SPIVAK, 2010). Desse modo, ao dizer que esse subalterno não pode falar, a autora não afirma necessariamente que não haja "clamor" ou protesto, mas que não chega a se estabelecer uma relação dialógica, ou melhor, não há um trânsito da voz entre falante e ouvinte, não há enunciação.

É imprescindível ressaltar que uma prerrogativa para estes estudiosos da subalternidade é o direito a recontar a história do seu país. Esta parece ser uma resposta ao processo imperialista (GUHA 1882; GUHA; SPIVAK, 1988; SPIVAK, 2004, 2010; BHABHA, 2005). Visto como uma forma de superação da subalternidade, o Grupo de Estudos Subalternos Sul-Asiático reescreve a história propondo uma "história alternativa com

ciência e sociedade. Pode o subalterno falar? Publicado em 1988, parece ser uma das obras mais importantes de seu percurso intelectual. O texto foi traduzido e discutido, debatido e criticado.

Anu. Lit., Florianópolis, v. 20, n. 1, p. 74-95, 2015. ISSNe 2175-7917 
relação ao discurso oficial dos historiadores que se inscreviam na ideologia de suas alianças políticas com a raj inglesa" (FIGUEIREDO, 2010, p. 85).

Com isso os autores deixam clara a perspectiva política pano de fundo das suas proposições teóricas. Convocando:

\begin{abstract}
para um processo de descolonização que vai além dos rompimentos de laços de dependência político administrativos. Passava pela crítica da própria ideia de cultura, inscrita na superfície do corpo com as tintas de um cientificismo que fala de raça como desigualdade, como patologia e degeneração (PELÚCIO, 2012, p. 399).
\end{abstract}

Outro ponto que não posso deixar de evidenciar é que as definições e teorizações acerca do conceito de subalternidade e do subalterno são resultado da passagem do lugar deste, que é considerado "o outro" na produção científica, o objeto de pesquisa para o lugar do pesquisador de sujeito, "do falante" como fica explícito a seguir:

\begin{abstract}
as críticas que emergem do feminismo, dos estudos culturais e do movimento negro àquelas que geraram um questionamento da legitimidade da representação (tanto estética quanto política) ao "interrogar os sistemas de poder que autorizam certas representações enquanto que outras são obstaculizadas, proibidas ou invalidadas”. Dito de outro modo, o que vai ser produzido a partir dos anos 60 é um deslocamento do sujeito da enunciação científica. Aqueles que até agora haviam sido produzidos como objetos abjetos do saber médico, psiquiátrico, antropológico, os "subalternos" (Guha, Spivak), os "anormais" (Foucault), vão reclamar progressivamente a produção de um saber local, um saber sobre si mesmos, um saber que questiona o saber hegemônico. É o que Foucault denomina em 1976 "a insurreição dos saberes sujeitados" (CARRILO, 2007, p. 61).
\end{abstract}

Nesses termos, "subalterno" é tomado como um conceito que se refere à perspectiva de pessoas de regiões e grupos que estão à margem na disputa por poder da estrutura hegemônica. Este enfoque se recusa a pensar a subalternidade a partir de uma perspectiva essencializadora, relacionado apenas com o colonial ou o pré-moderno. Ao contrário, compreende a subalternidade como "um conceito para designar o novo sujeito que emergia nos interditos da globalização" (BEVERLEY, 2003, p. 337, tradução nossa). A Subalternidade é aqui abordada como uma posição subjetiva relacional de complementaridade, não uma identidade, mas uma resultante e uma produtora de relações de poder que regem uma sociedade injusta. Nestes termos as inquietantes reflexões de Gayatri Spivak sobre a (im)possibilidade de fala dos subalternos e dos subalternos formam uma trama de sentidos que, em muito, contribui para a compreensão das relações desiguais e subalternizações no contexto social. Por este motivo, me proponho aqui a trazer as principais ideias apresentadas pela autora no texto Can the subaltern speak?, publicado em 1982 e recentemente traduzido para o português por Sandra Almeida, Marcos Feitosa e André Feitosa (2010). 


\section{Pode o subalterno falar?}

Com um título sugestivo e provocador, a intelectual indiana, Gayatri Chakravorty Spivak (2010), aborda, a partir da "paisagem” da colonização da Índia pela Inglaterra e do ritual de Sati praticado pelas mulheres viúvas, a possibilidade de atuação de uma intelectualidade periférica e/ou a possibilidade de fala do subalterno. No ensaio Spivak (2010) tece um emaranhado de elementos para se aproximar de respostas sobre se e como os subalternos foram forçadamente calados, silenciados.

A intelectual tem estruturado seu pensamento na interface com os feminismos, a corrente marxista, a perspectiva desconstrucionista e pós-colonial. É certo que todas estas vertentes reunidas têm resultado em um pensamento pós-colonial complexo e alcançá-lo tem sido um desafio. Mais do que somar perspectiva a autora coloca-as em diálogo explicitando suas aproximações e distanciamento, assim como, propondo novos caminhos (SPIVAK, 1994). Gayatri foge de classificações fáceis, e exige que complexifique a relação entre subalternidade, oriente, raça e gênero.

Spivak (2010) traz para o centro da discussão a produção intelectual não hegemônica que tem sido produzida no interior da academia. Reconhece "a quase" inexistência da possibilidade de um potencial contra hegemônico e mostra-se disposta, ainda que sem uma saída explícita, a aventurar-se na busca de uma "outra ciência", uma ciência contra hegemônica (VERÇOZA, 2012).

Em um texto complexo e denso, Gayatri reflete sobre a supremacia masculina na produção científica colonial. Discorre sobre o silêncio das mulheres, enfatizando que a "mudez" feminina - termo usado pela autora - configura-se na necessidade do reposicionamento das mulheres no espaço social, dizendo da importância do exercício de fala. Spivak (2010) conclui que o subalterno não pode falar, e que a posição da mulher subalterna é ainda mais grave.

Uma vez posta à margem da sociedade no contexto da produção colonial em que o homem é o dominante, a mulher subalterna não tem história e não pode falar, sendo colocada às sombras. A pesquisadora afirma que tal reflexão sobre a mulher não pode ser reduzida a uma mera questão idealista, uma vez que ignorar o debate acerca da mulher subalterna seria um gesto apolítico que, ao longo da história, tem perpetuado o radicalismo masculino (FIGUEIREDO, 2010, p. 87).

O que está em jogo nas proposições de Spivak é o que é tido como verdade, e quem teve que perder a voz para que as verdades se tornassem "a verdade". A autora propõe uma releitura sobre a verdade ao transportar esse debate para outro lugar: a capacidade do subalterno de representar-se (FIGUEIREDO, 2009). 
Spivak (2010) se lança em busca da pergunta tema de seu texto por diversas vezes, em um movimento de crítica a teorias e teóricos que vão falar pelo subalterno e com o subalterno, mas não irão constituir um espaço para que o subalterno fale. Afirma que produções deste tipo estão pactuando com um modelo hegemônico de ciência e com um projeto imperialista de sociedade, realizando, dessa forma, críticas a Foucault, ancoradas em uma forte influência de Derrida. "Spivak aponta a 'violência epistêmica' à que a ciência, aquela mesma que Foucault critica, submeteu os saberes gestados fora de seus cânones e, assim, os sujeitos produtores desses saberes" (PELÚCIO, 2012, p.402). Violência esta, em que a tática de neutralização do Outro, seja ele subalterno ou colonizado, consiste em invisibilizá-lo, expropriando-o de qualquer possibilidade de representação, silenciando-o. Igual erro incorreu Foucault em suas teorizações sobre os saberes sujeitados, reproduzindo a mesma lógica imperialista e eurocentrada, tão questionada e contestada pelos estudiosos póscoloniais (SPIVAK, 2010). Para Spivak (2010) Foucault permaneceu exercendo uma função, que tradicionalmente era desempenhada por intelectuais imperialistas, ser porta-voz e orientadores das massas subalternas.

Ao nomear a violência imperialista produtora do silêncio dos subalternos, Spivak (2010) discorre tanto sobre suas consequências epistêmicas quanto suas consequências sóciopolíticas. No campo epistemológico a autora discorre sobre o projeto de ciência que impede que os subalternos se autorrepresentem, em outros termos, os subalternos não angariam lugar de sujeitos no campo científico hegemônico moderno, não sendo reconhecidos como autores de um discurso que represente a própria vivência social.

Assim diante do reconhecimento, do que Spivak (2010) nomeou como violência epistemológica, onde é retirada a possibilidade de alguns sujeitos colocarem em disputa a história sobre a sociedade a partir de sua cultura, a autora aponta que uma tarefa do intelectual é, justamente, de reescrever a história, se atentando à experiência do seu país de Origem, a Índia (NEVES, 2010). Nesse sentido o objetivo dos Estudos Subalternos é relatar o que foi ocultado pela historiografia oficial. Proponho aqui pensarmos um pouco mais além: Quais os efeitos de poder da ausência da história? Dois caminhos se delineiam na busca de uma possível resposta. O primeiro diz respeito ao não reconhecimento de alguns como sujeitos, e não sendo sujeito não há enunciação. O segundo é a manutenção de um certo status quo, dito de outro modo, o desejo da imutabilidade do presente.

Segundo a teórica, a "resposta" à violência epistemológica é, justamente, uma prática rigorosa de desconstrução histórica, o que é, muitas vezes, dificultado pela ausência de fontes 
atendíveis, precisamente pela falta de legitimidade das vozes de povos a quem nunca se permitiu que falasse (NEVES, 2010). Mas o grupo de teóricos dos Estudos Subalternos desejava, no entanto, ir além da noção da "história dos subalternos", ou dito de outro modo, da história descrita a partir da perspectiva das classes dominadas, propondo uma autorreflexão acerca do lugar social do subalterno e de suas consequências políticas. $\mathrm{O}$ projeto de reelaboração da história, que tudo tem a ver com o desejo de libertação nacionalista, contribui para a construção de uma teórica crítica, o questionamento da neutralidade da ciência, a partir da consciência da condição de subalternidade em que grupos e sujeitos de encontram. Nesse sentido, as teorizações se detêm nos processos a partir dos quais os sujeitos, no espaço e na história, transformam-se em categorias e se circunscreve nos processos indenitários e nas identidades coletivas.

Para Spivak (2010), a ideia de "consciência subalterna", que representa uma "consciência coletiva", constitui um dos temas fundamentais dos Estudos Subalternos. Os estudiosos da "corrente subalterna" desenvolveram suas teorias a partir da construção do que podemos nomear como a historiografia do outro e o conceito de consciência subalterna esta perspectiva confronta-se diretamente com a teoria marxista (SPIVAK, 1999). Spivak (2004) recusa a consciência de classe do subalterno pré-capitalista, sobretudo no cenário do imperialismo, a "consciência subalterna" não é natural, nem parte da essência dos integrantes deste grupo, ao contrário, é uma construção coletiva do seu lugar como subalterno, as relações de poder que produzem e reiteram o lugar destes como subalternos e o desenvolvimento de respostas diante destas constatações. Assim a "consciência subalterna" implica no reconhecimento da agência do subalterno.

No campo sócio-político, Gayatri (2010) pondera sobre o Sati e afirma que a mulher viúva, no contexto indiano, é duplamente impedida de se representar, por um lado, por ser mulher e, por outro, por sua condição de viuvez. O antigo ritual praticado pelos hindus, e atualmente proibido pelas leis indianas, obrigava as viúvas a se sacrificarem na fogueira da pira funerária de seu marido morto. Mesmo que na contemporaneidade a prática do Sati não seja, frequentemente praticado, as mulheres viúvas indianas ainda são penalizada, já que são, indiretamente, responsabilizadas pela morte dos maridos sendo as "portadoras da má sorte para a família que passa a fazer parte após o casamento". Nestes termos a viúva:

no desempenhar de sua função enquanto esposa, deve abdicar de sua própria vida, submetendo-se ao sacrifício 'por vontade própria' e diante da morte de seu marido, pois do contrário não se libertará de seu corpo feminino e de sua função biológica, segundo os preceitos desse rito (ENEDINO; SOUSA, 2014, p. 372). 
Spivak (2010) ao apresentar o ritual Sati, o faz, para salvar seu próprio corpo em futuras encarnações, a autora apresenta o viés colonizante e múltiplo das experiências de ser mulher (CRUZ, 2011). Dispondo-se de detalhes deste exemplo da cultura indiana tradicional, a autora afirma que a situação de marginalidade e inferiorização dos subalternos é mais duramente imposta aos corpos de mulheres, posto que a "mulher como subalterna não pode falar e, quando tenta fazê-lo, não encontra os meios para se fazer ouvir” (SPIVAK, 2010, p. 15). A mulher viúva não pode ser ouvida nem pelo discurso colonizador nem pela sociedade hindu. Assim, Spivak (2010), mais uma vez, conclui que o subalterno não pode falar, e que a posição da mulher subalterna é ainda mais grave.

Por fim, Spivak, através do exemplo do Sati, tenta ouvir a voz da mulher pobre e indiana. Se em um primeiro momento o Sati parece apontar que não há saída, a religião, a sociedade hindu e os colonizadores, condenam as viúvas a serem mulheres de um morto mantendo-se mortas em vida. Em outro o suicídio pode ser visto, ao mesmo tempo como fala e silêncio ao contemplar a possibilidade de uma re-apropriação do corpo em um ato de livre vontade e o silêncio perpétuo de sua voz. Ao afirmar que as mulheres, assim como outros subalternos, não podiam falar, o faz como uma conclusão relativa, já que, apresenta o silenciamento, ao mesmo tempo em que, a enunciação. Há uma livre vontade no autoextermínio no Sati.

Assim, nas suas proposições, a condição subalterna é o silêncio. O subalterno, nestes termos, são aqueles que não conseguem lugar em um contexto globalizante, capitalista, totalitário e excludente. O subalterno carece, fundamentalmente, de alguém que o represente por sua condição de silenciado (FIGUEIREDO, 2010). Para Spivak (2010), há uma relação direta entre falar por e representar, onde ambos podem cair no vazio da invisibilidade do subalterno. Tanto o "falar por" quanto o "representar" exigem um falante e um ouvinte, o que caracterizaria um diálogo. Para a autora, este espaço dialógico não existe para o subalterno, que termina invariavelmente no silêncio, ou melhor, na surdez do outro. Ao mesmo tempo em que enfatiza a necessidade de criar, por parte dos intelectuais, formas de deixar os subalternos se fazerem ouvir.

Para usar uma conhecida metáfora de GayatriSpivak, o que começou como um portrait - representação, no sentido de "falar" - tornou-se proxy — representação, no sentido de falar por - e que apareceu como que algo interrompia ou ultrapassava a lógica capital do estado moderno - a proliferação de heterogeneidade cultural para além dos limites da "cidade letrada" e pedagógico hegemônico de cultura tornou-se novamente um problema da razão de Estado e com a colaboração da instituição acadêmica com a razão (BEVERLEY, 2003, p. 337, tradução nossa). 
Se a condição de subalternidade é o silêncio, silêncio este que exclui a possibilidade de autorrepresentação dos sujeitos e o que resta a eles é serem representados por outrem, a afirmativa nos conduz novamente para a instigante pergunta da autora: pode o subalterno angariar o lugar de fala? (FIGUEIREDO, 2010). Para alguns esta pergunta parece demasiadamente otimista e distante da resposta dada por Spivak, mas, se associada ao grupo teórico em que ela compõe, a minha leitura é "menos romantizada": a fala só é possível a partir do momento em que propormos, tal como ela faz, a produção - cientifica, política, social e econômica - de uma história em que a narrativa dos subalternos esteja em foco. $\mathrm{O}$ certo é que a possível maneira de colocar o subalterno para falar não é "doando-lhe voz", ou falando por ele, mas problematizando como diferenças se tornam desigualdades sociais e desvelando relações de poder que constituem normativas sobre os sujeitos. Nesses termos, o subalterno passa a falar quando encontra na esfera pública reconhecimento e legitimidade de fala.

Pelúcio (2012) aponta que Spivak dá uma resposta pouco promissora à pergunta título de sua obra: Pode o subalterno falar?. Segundo referida autora:

\begin{abstract}
A autora mostra que é ilusória a referência a um sujeito subalterno que pudesse falar. O que ela constata, valendo-se do exemplo da Índia, é uma heterogeneidade de subalternos, os quais não são possuidores de uma consciência autêntica pré- ou póscolonial, trata-se de "subjetividades precárias" construídas no marco da "violência epistêmica" colonial (PELÚCIO, 2012, p. 402).
\end{abstract}

Com esta afirmação, para Pelúcio (2012), o que Spivak nomeia é que alguns sujeitos têm sua faculdade de enunciação, sobre si e sobre o mundo, roubada, são sujeitos desqualificados a priori do lugar de fala. Ao refletir sobre as mulheres como um sujeito subalterno, Spivak (2010) explicita a marginalidade destas, como na cena científica colonial, que segundo ela e em consonância com muitas teóricas feministas, é dominado pelo masculino. A autora não aponta caminhos para que as mulheres libertem-se do estigma da subordinação, sendo intensamente crítica, sob justificativa da impossibilidade de mudança social e a incoerência entre seu lugar social e sua produção intelectual.

Spivak (2010) conclui seu texto afirmando:

O subalterno não pode falar. Não há valor algum atribuído à mulher como um item respeitoso nas listas de prioridade global. A representação não definhou. A mulher intelectual como intelectual tem uma tarefa circunscrita que ela não deve rejeitar com um floreio (SPIVAK, 2010, p. 126).

Sandra Almeida (2010), ao discorrer sobre a conclusão a que Spivak (2010) chega em sua obra, considera que a autora vai além de uma resposta rápida e objetiva. Para ela, sua 
conclusão "refere-se ao fato de a fala do subalterno e do colonizado ser sempre intermediada pela voz de outrem, que se coloca em posição de reivindicar algo em nome de um(a) outro(a)" (ALMEIDA, 2010, p. 26).

Não há um consenso sobre o cunho propositivo ou sobre a resignação nas teorizações de Spivak (2010). Se por um lado alguns vão nomear as proposições de Gayatri como uma teórica que não propõe nenhuma saída da condição de inferiorização dos subalternos (MUYLAERT, 2005; MAGGIO, 2007; PELÚCIO, 2012). Outros vão pontuar que ela assume uma postura firme e corajosa ao afirmar que a responsabilidade pelo combate à subalternidade é papel dos intelectuais (ALMEIDA, 2010; CARVALHO, 2011). Inúmeras críticas são feitas ao pensamento da intelectual. Alguns questionam a sua legitimidade e seus objetivos políticos, outros interrogam seus pressupostos teóricos e suas implicações sócio-históricas (EAGLETON, 2003; MAGGIO, 2007). Talvez o ponto central do debate deste ensaio seja a busca por estruturas teóricas, textuais, sociais e políticas que possam propiciar a emergência de vozes que foram silenciadas por forças políticas imperialistas (ALMEIDA, 2010; PATROCÍNIO, 2010; CRUZ, 2011).

Enquanto, para alguns teóricos, Gayatri Spivak apontou para um horizonte de apagamento sistemático da voz dos subalternos, Chandra Mohanty e Jacqui Alexander (1997), em resposta à afirmação do silêncio dos subalternos, propuseram o seu reconhecimento como sujeito. Dessa maneira, o subalterno não está condenado ao silêncio, mas, ao contrário, se encontra nas fraturas entre os discursos hegemônicos e os discursos das minorias. Para estas autoras, aí está a dificuldade de escuta destes atores. Assim, contrariamente a Spivak, Mohanty e Alexander (1997) se dedicam em mostrar como o sujeito subalterno produz linguagens, ainda que minoritárias.

Maggio (2007), ao realizar duras críticas a Spivak, afirma que dentre os vários erros nas proposições da autora está a sua pergunta (pode o subalterno falar?). Para o autor, o questionamento certo a se fazer é referente à possibilidade de escuta do subalterno. Assim, questiona-se se o subalterno pode ser ouvido, já que para ele é óbvio que o subalterno fale.

Para Maggio (2007) o subalterno não consegue ser ouvido, em contrapartida Mohanty e Alexander (1997) apontam que além de falarem são ouvidos. Falam numa língua dos subalternos, língua esta que só pode existir a partir de um alocamento de toda linguagem como fronteiriça passível de "tradução, de contaminação, de deslocamento, negando o caráter originário e puro da linguagem e, por extensão, da identidade nacional, mas também de gênero e sexual” (CARRILO, 2007, p. 61). Assim, questiona-se a concepção de uma língua 
una e indivisível que exclui qualquer variação social inerente. Os subalternos, ao falarem, a partir de uma língua não dominante, não produzem apenas distorções de sentido, mas redesenham significados e linguagens.

Se por um lado teóricos tentam esculpir negociações positivas com a lógica epistêmica do imperialismo Spivak (2010) rompe com os limites de compatibilidade (MELUCCI, 2001), com o sistema imperialista. Há um caráter radical em seu pensamento. É difícil ver como qualquer um pode escrever.

Muitas vezes acusada de vitimizar os subalternos e colocá-los em uma posição sem uma saída possível Spivak (2010) instaurou um debate, colocou em xeque interpretações e produziu um conhecimento local e limitado. Ao lançar luz sobre uma possível agência do sujeito Spivak (2010) parece ser uma subalterna que passa a ver, ouvir e falar sem o manto da subordinação. Nomeou, a partir de uma consciência subalterna, relações sociais como relações de poder. Utilizou-se da ciência como campo simbólico (BOURDIEU, 1983) na constituição de uma outra história ou da história dos outros.

Evidenciar a subalternidade como situacional e partir de posições mutáveis possibilita enxergarmos saídas e romper com a dicotomia entre sujeito consciente e sujeito subalterno. A consciência subalterna emerge nas relações e instaura contínuos entre o sujeito audível e o silenciado.

Spivak (2010), assim como teóricos dos Estudos Subalternos e Pós-coloniais, tenta mostrar como diferenças culturais se transformaram em assimetrias de poder, de acesso à esfera pública. A autora o faz, explicitando o discurso imperial a que indianos, mulheres e negras estão submetidos. O que Gayatri parece fazer é questionar a assimetria entre subalternos e "senhores", nomeando a desigualdade que se estabelece nesta relação como “colonial”, antes que "cultural”. Ou seja, é a diferença que justifica a exploração, o controle e a dominação de um setor da população sobre outros. A desigualdade de gênero, a racialização, entre outros são consequências da diferença colonial. A produção desta diferença colonial remete à libertação dos poderes imperiais epistêmicos. A descolonização epistêmica define, silencia e hierarquiza grupos e povos.

Também, não há uma resposta fácil ao questionamento sobre o caráter emancipatório ou resignado das teorizações de Spivak (2010). Muitos estudos se posicionam nesta seara (MOHANTY; JACQUI, 1997; MUYLAERT, 2005; MAGGIO, 2007; CARRILO, 2007; DURÃO, 2009; FIGUEIREDO, 2009, 2010; ALMEIDA, 2010; CARVALHO, 2011; CRUZ, 2011; PELÚCIO, 2012). Durante parte considerável do meu processo reflexivo acerca da 
subalternidade me posicionei ao lado dos que reconhecem a impossibilidade de agência do subalterno nos ditos de Spivak. Após uma imersão em textos posteriores como Quem reivindica alteridade? (1994), o original publicado em 1989, El desplazamiento y el discurso de la mujer (1994), A Critique of Postcolonial Reason: towards a history of the vanishing present (1999), e em autores que tentam interpretá-la me direcionei para outro caminho, que recusa a resignação e vislumbra saídas possíveis. Mas, mesmo sabendo que em vinte anos o pensamento da autora tem alterações, a pergunta sobre a possibilidade de fala dos subalternos se mantém em voga, não há uma resposta pronta da autora, mas a pergunta sobre a transformação da realidade vigente, a mudança social, a agência possível. Minha hipótese é a de que, possivelmente, o ponto mais importante deste ensaio, Pode o subalterno falar?, seja a procura por meios teóricos e textuais que favoreçam a manifestação de vozes que foram sulcadas por forças políticas dominantes (MOHANTY; JACQUI, 1997; ALMEIDA, 2010; PATROCÍNIO, 2010; CRUZ, 2011). Esta hipótese aponta para um combate à ideia de um apagamento sistemático da voz dos subalternos.

Dessa forma partilho dos argumentos de Chandra Mohanty e Alexander Jacqui (1997) que defendem a ideia que de o subalterno não está fadado ao silêncio, mas, ao contrário, tem resistido às dinâmicas de silenciamento. Para os autores, os subalternos, certamente, falam, mas como aponta Anzaldúa (2000), falam em línguas, em outras palavras, a fala dos subalternos encontram-se nas fraturas entre vários discursos, entre os discursos hegemônicos e minoritários, e aí se aloca a dificuldade de escuta. Nesses termos, o sujeito pós-colonial, as mulheres, os negros, os trabalhadores e outros falam e produzem linguagens específicas.

As reflexões realizadas até aqui explicitam o começo de um diálogo com a teórica Spivak, principalmente, a partir do texto Pode o Subalterno Falar?. O pensamento de Spivak tem trazido perguntas instigantes quanto à representatividade das subalternas e a possibilidade de fala destas. Longe de encontrar respostas fáceis, Gayatri traz apontamentos intrigantes sobre o lugar "dos outros" nas esferas sociais. O ensaio instaurou um debate acerca da possibilidade de agência dos subalternos. Desde então, uma polêmica tem perdurado: se o subalterno não pode falar, e quando fala deixa de ser subalterno? Como se dá a passagem entre fala e silêncio? A partir de quais dinâmicas alguns se tornam falantes e outros mudos? O que significa falar?

\section{Posições de subalternidade: desnaturalizando lugares}


O falar que compõe a pergunta de Spivak (2010) não se resume apenas ao seu significado no "estrito senso", mas também, a ele. De fato, apesar dessa noção não ser diretamente abordada no texto, os estudos sociológicos de Pierre Bourdieu (1996) e linguísticos de Eni Orlandi (2007) evidenciam que a linguagem sempre foi um instrumento de poder nas relações entre as pessoas, nas relações de dominação. Assim, da mesma forma em que a linguagem é o meio pelo qual se dá o diálogo, ela também exclui da comunicação aqueles que não compartilham o seu léxico.

O que significa falar não é um questionamento carregado de originalidade. No campo sociológico, Pierre Bourdieu (1996) já o fez em 1982, no A Economia das Trocas Linguísticas: O que falar quer dizer, obra traduzida recentemente para o português. Bourdieu se pergunta sobre o significado do evento da comunicação e suas consequências sóciopolíticas. Para ele a comunicação é o resultado de trocas linguísticas, estas, por sua vez, são, antes de tudo, relações carregadas de poder simbólico. É na linguagem que relações de força entre os locutores ou os seus ouvintes se estabelecem.

Bourdieu (1996) pondera sobre a linguagem em seu sentido sociológico e elabora uma teoria do poder simbólico a partir de uma crítica aos postulados da linguística. O autor busca construir os sistemas de disposições sociais dos diversos grupos e seu traquejo com a língua como parte de um domínio particular e distintivo do corpo. Nomeia as trocas linguísticas como relações de comunicação e de poder simbólico, onde se (re)atualizam relações de força entre os locutores ou seus ouvintes. Pontua que todo ato de falar implica em uma relação entre disposições socialmente modeladas do habitus ${ }^{2}$ linguístico e as estruturas do mercado linguístico. Este, por sua vez, se impõe como um sistema de normas, sanções e censuras específicas a cada grupo. Sendo assim, o que circula no mercado linguístico não é "a língua", mas discursos sobre a língua. A luta pela autoridade linguística evidencia que a palavra só existe imersa em situações, na disputa se estabelece o que é legítimo e o que não o é.

É certo que o falar é parte de uma competência biológica, comum a todos os seres humanos, portanto, não distintiva. Mas a legitimidade da fala é construída socialmente e, portanto, capaz de propiciar a distinção. Assim o reconhecimento da fala está no falar uma

\footnotetext{
${ }^{2}$ O Conceito de habitus para Bourdieu (1996) diz de sistemas de posições duráveis e transferíveis que, integrando todas as experiências passadas, funciona a cada instante como uma matriz de percepções, apreciações e ações, e torna possível a realização de tarefas infinitamente diferenciadas. Em outras palavras diz respeito às disposições incorporadas pelos sujeitos sociais ao longo de seu processo de socialização. Segundo o autor: "habitus é um operador, uma matriz de percepção e não uma identidade ou uma subjetividade fixa" (BOURDIEU, 2002, p. 83).
} 
língua legítima (BOURDIEU, 1996). Dito de outro modo, as práticas linguísticas são resultado de disputas por reconhecimento. Buscam tornar práticas de linguagem em práticas de legitimidade. Nesta perspectiva, os falantes são os portadores das mudanças sociais. Na mesma direção, Gnerre (1985, p. 22) aponta que "a linguagem constitui o arame farpado mais poderoso para bloquear o acesso ao poder".

No campo linguístico a teórica Eni Orlandi (2007), pesquisadora da linguagem, em uma investigação sobre o silêncio, em seu sentido literal, se atenta à composição deste na linguagem. A autora entende a linguagem como uma construção social de sentidos e do silêncio, em outros termos, a ausência da fala, do som, compõe a linguagem tanto nas lacunas nas quais ele se insere quanto no "som que o silêncio produz".

$\mathrm{Na}$ tentativa de encontrar caminhos para o fim do silêncio de grupos subalternos, Spivak (2010) apresenta um projeto de fala a partir da reescrita da história, em outras palavras, reescrever o desenvolvimento da consciência da nação indiana. A autora denuncia a criação do não falante através do ato de "tornar visíveis os mecanismos médicos e jurídicos que permeiam a história" (SPIVAK, 2010, p. 61), a esses mecanismos podemos acrescentar os científicos. Spivak procura encontrar meios para que o subalterno seja ouvido. Nestes termos o silêncio que invade o diálogo é, de fato, um paradoxo. Um silêncio que precisa ecoar, que deseja passar pela linguagem e se transformar em uma forma de discurso. Passar do não-dito para o dito, para Spivak (2010), é mais do que gostar do som. Isso não significa necessariamente saber falar. É se tornar sujeito, é ter um interlocutor. Assim, a ruptura com a subalternidade é o tornar-se sujeito, entendendo o sujeito como uma singularização dos aspectos mais amplos da sociedade e, a linguagem, como uma forma de ação política no mundo.

Dessa maneira, há novamente um encontro com a pergunta cerne das reflexões de Spivak: pode o subalterno falar? A resposta a essa questão não é simples, nem baseada em uma resposta linguística, mas, nas consequências sociopolíticas da enunciação. A analogia feita pela autora em relação à fala traz a enunciação para o campo do político. A fala aqui é entendida como reconhecimento social, legitimidade de sujeitos na construção de signos, símbolos e representações sociais, em outras palavras, o reconhecimento de alguns corpos como sujeitos e a participação destes na construção de sentidos na esfera pública.

Muitos se aventuraram na pergunta de Spivak. Alguns, sem sucesso, questionaram a impossibilidade de agência em suas proposições teóricas (EAGLETON, 2003; MUYLAERT, 2005; MAGGIO, 2007; PELÚCIO, 2012), outros abordaram a subalternidade como parte de 
uma essência dos sujeitos (FIGUEIREDO, 2010). Há ainda os que questionaram a impossibilidade de fala dos subalternos.

Todo esse diálogo teórico trouxe uma outra possibilidade interpretativa, em outras palavras, uma nova pergunta. A pergunta sobre quem é o subalterno foi substituída por quais mecanismos de legitimidade e deslegitimação são acionados para identificar corpos como subalternos ou não. E, ainda, quais as consequências na estruturação de um campo de pensamento científico. Assim, passa a ser interesse compreender como os corpos se tornam matéria. Vale ressaltar que esta mudança não me distancia da resposta à pergunta de Spivak (2010), somente dá a ela uma nova roupagem, isto é, redesenha caminhos para se pensar a fala subalterna.

As teorizações propostas pelo grupo de pesquisadores indianos que integram os "Estudos Subalternos" nos levam a questionar se eles próprios não seriam exemplos de subalternos que ganham o lócus enunciativo. Seriam eles sujeitos subalternos que conseguiram falar? Tornarem-se intelectuais os tiram do lugar de subalternos?

Diante destas novas perguntas e me atentando às implicações sociais, políticas e científicas da impossibilidade de fala, retornei ao texto de Spivak (2010). A definição de Spivak (2010) de que a condição subalterna é o silêncio se baseia na constatação de que, como objeto, o subalterno possui uma voz que é ausente de uma mediação do código linguístico e cultural colonial/hegemônico (PATROCÍNIO, 2010). Nestes termos o silêncio do subalterno é a condição de não participação na esfera social. Assim a posição subalterna é a impossibilidade do reconhecimento do subalterno como sujeito. A saída da posição de subalternidade, nesta proposta, é, justamente, a nomeação da agência.

As teorizações de Enerst Laclau e Chantal Mouffe (1985) auxiliam na compressão de que o rompimento com uma posição subalterna representaria a passagem de uma relação de subordinação para uma relação de opressão. Nesse ponto, reconheço o caráter eminentemente político da posição subalterna, questiono os porquês do estabelecimento dessas desigualdades e seus pressupostos. Vale ressaltar que a passagem do lócus subalterno para o lócus enunciativo se dá na produção do que Spivak (2010) vai nomear como consciência subalterna. A passagem para o lócus enunciativo é também interpretada como a consciência da situação de opressão e o estabelecimento de antagonismos sociais. O antagonismo entre subalterno e "colonizador" não é inerente à relação social, ela é proveniente desta.

Nesse sentido, a consciência subalterna se faz possível mediante ao reconhecimento de uma injustiça social que resulta na vivência de uma posição subalterna, desvelando 
relações de poder e resultando na passagem de uma relação de subordinação para a condição de opressão (COSTA, 2010). A condição de opressão possibilita a agência dos sujeitos, podendo resultar no enfrentado pela ação mobilizadora de demandas por equivalência, sejam elas coletivas ou individuais (PRADO, 2002). Assim a consciência subalterna resulta na percepção de fronteiras vividas e experienciadas, não como diferenciações sociais entre grupos, mas como impedimentos sociais e políticos na conquista da equivalência de direitos (MOUFFE, 1995; 1988).

Laclau e Mouffe (1985) acreditam que os sujeitos estão posicionados no interior de sistemas hierárquicos que os antecede e que limitam as possibilidades destes interpretarem o mundo, sendo que a percepção dessas restrições possibilitam a instauração de conflitos sociais e lutas por redefinições de si e do mundo. A lógica de equivalência acarreta na disputa de direitos e na redefinição dos antagonismos democráticos na construção de um projeto contrahegemônico (LACLAU, 1993). Com isso, o subalterno pode emergir como um sujeito político e afirmar uma nova positividade do social (COSTA, 2010). Assim, a consciência subalterna resulta em lutas por equivalência e justiça social.

Assim a "consciência subalterna" é a capacidade de denunciar o estado das coisas. Não se trata de um estado natural, mas de algo que pode ser construído de maneiras diversas, atendendo a razões coloniais e desiguais. Ou dito de outro modo, diz da capacidade de os subalternos se tornarem sujeitos. Para tanto, estes adquirem, a partir da indagação, outras possibilidades nas relações com o mundo. O processo de "conscientização" caracteriza-se por uma postura crítica do sujeito frente às relações em que está inserido. O sujeito critica na medida em que é capaz de indagar-se. Essa indagação, por sua vez, devolve as possibilidades de existência para além daquela que os dominadores oferecem.

Spivak (2010) aponta para o caráter eminentemente político das relações de subalternidade. Assim, em uma perspectiva de ampliação do conceito, recorro às proposições de Chantal Mouffe (1999), ao afirmar que a função da política é visibilizar relações conflituosas na esfera pública. Dessa forma, a consciência da subalternidade seria a explicitação, na arena pública, das desigualdades. As relações de poder são inerentes à disputa pela instauração de novas inteligibilidades acerca do subalterno. A consciência de uma posição subalterna é, justamente, o movimento de colocar em jogo os interesses de alguns que se sobrepõe ao interesse de outros. Uma consciência do lugar subalterno baseia-se na passagem de uma relação de subordinação para uma consciência de opressão. Em outras 
palavras, publiciza as relações de poder e estabelece as fronteiras políticas, havendo, assim, a possibilidade de mudanças sociais (PRADO, 2002).

Nestes termos as noções de relações de opressão e de subordinação são importantes para pensarmos a condição de subalternidade e a posição subalterna. Nas relações de subordinação não há a percepção histórica da ordem social, sendo a inferiorização e a subalternização naturalizadas (LACLAU, MOUFFE, 1985; PRADO, 2002). Já nas relações de opressão há reflexão e percepção da historicidade das construções sociais, que possibilitam o estabelecimento de antagonismos entre os agentes (PRADO, 2002).

A conscientização da condição de opressão proposta por Laclau e Mouffe (1985) e abordada por Prado (2002), aponta para a demarcação de fronteiras políticas, o que implica no reconhecimento de que o eles e o nós são irreconciliáveis. Em diálogo com a "consciência subalterna" de Spivak (2010), é possível afirmar que o reconhecimento de que o colonizador impede a fala do subalterno e de que a conscientização é o direito de transformar espaços sociais em espaços de lutas políticas, na tentativa do estabelecimento das relações de reciprocidade (MELUCCI, 1996), sejam elas de reconhecimento negativo ou positivo, há sustentação da necessidade de se definir o consenso do nós. O que significa redefinir o conjunto de valores, crenças, interesses e significados de que este nós é portador, e há, também, a necessidade de reconhecer o caráter precário deste consenso, desde que o eles é um constitutivo exterior internalizado pelo nós, e que garante a continuidade de suas relações de pertença.

Compreender a subalternidade como uma posição e não como uma condição social me coloca em um lugar de análise das falas e dos silenciamentos. Há de se ressaltar que estes lugares não estanques possibilitam pensar no trânsito entre lugares, posições subalternas e lugares de agência. Nestes termos a história tem demonstrado que alguns sujeitos parecem manter-se durante muito tempo em posições de subalternidade. Os negros, as mulheres, os pós-coloniais, entre outros.

\section{Referências}

ALMEIDA, Sandra. Regina Goulart. Prefácio: apresentando Spivak. In: SPIVAK, G. C. Pode o Subalterno Falar?. Tradução de Sandra Regina Goulart Almeida; Marco Pereira Feitosa; André Pereira Feitosa. Belo Horizonte: Editora UFMG, p.1-23, 2010.

ANZALDÚA, Gloria Evelina. Falando em línguas: uma carta para as mulheres escritoras do Terceiro Mundo. Revista Estudos Feministas, Florianópolis, n. 8, v.1, p.229-236, 2000. 
BEVERLEY, John. Subalternidad y representación: debates en teoría cultural. Tradução de M. Beiza; S. Villalobos-Ruminott. Madrid: Iberoamericana, 2003.

BHABHA, Homi K. O local da cultura. Belo Horizonte: Editora. UFMG, (Coleção Humanitas), 2005.

BOURDEIU, Pierre. O campo científico. In: ORTIZ, Renato (Org.). Bourdieu - Sociologia. São Paulo: Ática (Coleção Grandes Cientistas Sociais), p. 122-155, 1983.

1996.

. A Economia das Trocas Linguísticas: O que falar quer dizer. São Paulo: EDUSP,

CARRILlO, Jesús. Entrevista com Beatriz Preciado. Cadernos Pagu, n. 28, p.375-405, 2007.

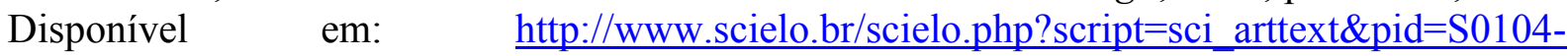

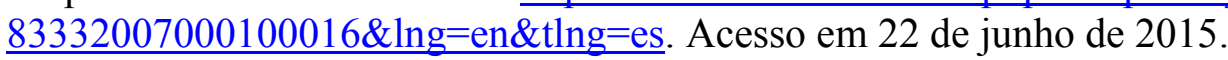

CARVALHO, Bruno Sciberras de. Subalternidade e possibilidades de agência: uma crítica pós-colonialista. Revista Estudos Políticos, n. 3, v. 2, p. 65-69, 2011.

COSTA, Frederico Alves. Democratização social e pluralidade de sujeitos políticos [manuscrito]: 2010 uma leitura a partir da Teoria democrática radical e plural. 2010. Dissertação (Mestrado em Psicologia). - Programa de Pós-Graduação em Psicologia, Universidade Federal de Minas Gerais. Belo Horizonte, Minas Gerais.

CRUZ, Edna Sousa. Os sentidos do poder/saber dizer. Entreletras: Revista do Curso de Mestrado em Ensino de Língua e Literatura da UFT, n. 2, v. 3, p. 1-3, 2011.

DURÃO, Fabio Akcelrud. Da politização da desconstrução em Gayatri Spivak. Revista de Letras. São Paulo, n. 49, v. 2, p. 289-301, 2009.

EAGLETON, Terry. Figures of Dissent: Critical Essays on Fish, Spivak, Zizek, andOthers. London: Verso, 2003.

ENEDINO, Wagner Corsino; SOUZA, Celeste da Silva. Subalternidade, marginalidade e violência num tempo sem lei: uma leitura de Quêro, uma reportagem maldita e híbrida. Revista Estação Literária, n. 12, p. 370-387, 2014.

FIGUEIREDO, Carlos Vinícius da Silva. O direito ao grito: a hora do intelectual subalterno em Clarice Lispector. 2009. Dissertação (Mestrado em Letras) - Programa de Pós-Graduação em Letras, Universidade Federal de Mato Grosso do Sul, Três Lagoas, Mato Grosso do Sul.

. Estudos subalternos: uma introdução. Raído. Dourados, n. 4, v. 7, p.83-92, 2010.

GAGO, Verônica; OBARRIO, Juan. ¿Podemos oír al subalterno? Revista de Cultura, 2013. Disponível em: $\quad$ www.revistaenie.clarin.com/ideas/Gayatri-Spivakentrevista 0 1024097850.html. Acesso em 22 de junho de 2015.

GNERRE, Maurizzio. Linguagem, Escrita e Poder. São Paulo: Martins Fontes, 1985.

GRAMSCI, Antônio. Cadernos do cárcere. Rio de Janeiro: Editora Civilização Brasileira, v. $5,2002$. 
. Quaderni.del.Carcere. Torino: Einaudi, 2007.

GUHA, Ranajit. Subaltern Studies: Writingson South Asian Society and History. Vol. VII: Oxford, 1982.

GUHA, Ranajit; SPIVAK, Gayatri Chakravorty. Selected Subaltern Studies. New York: Oxford University Press, 1988.

LACLAU, Ernesto; MOUFFE, Chantal. Hegemony and Socialist Strategy: Towards a radical democratic politics. London: Verso, 1985.

LACLAU, Ernesto. Nuevas reflexiones sobre la revolución de nuestro tempo. In: LACLAU, E. Nuevas reflexiones sobre la revolución de nuestro tiempo. Buenos Aires: Ediciones Nueva Visión, p.19-99, 1993.

MAGGIO, J. “Can the Subaltern Be Heard?”: Political Theory, Translation, Representation, and Gayatri Chakravorty Spivak. Alternatives, n. 32, p. 419-443, 2007.

MELUCCI, Alberto. Challenging codes: colletive action in the information age. Cambridge: University Press, 1996.

Vozes, 2001.

A invenção do presente: movimentos sociais nas sociedades complexas. Petrópolis:

MOHANTY, Chandra Talpade; ALEXANDER, Jacqui. Feminist Genealogies, Colonial Legacies, Democratic Futures. London/New York: Routledge, 1997.

MOUFFE, Chantal. Hegemony and new political subjects: toward a new concept of democracy. In: NELSON, Cary; GROSSBERG, Lawrense. Marxism and the interpretation of culture. Chicago: University of Illinois Press, p. 89-101, 1988.

Democratic politics and the question of identity. In: RAJCHMAN, J. (Org.). The identity in question. New York: Routledge, p. 33-45, 1995.

. Carl Schmitt and the paradox of liberal democracy. In: MOUFFE, C. (Org.). The challenge of Carl Schmitt. Nova York: Verso, p. 38-53, 1999.

MUYLAERT, Elizabeth. Devires autobiográficos - a atualidade da escrita de si. 2005. Tese (Doutorado em Letras) - Programa da Pós-Graduação em Letras, Pontifícia Universidade Católica do Rio de Janeiro, Rio de Janeiro.

NEVES, Rita Ciotta. A perspectiva pós-colonial de Antoni Gramisci: os subalternos. Babilónia, n. 8, v. 9, p. 59-64, 2010.

ORLANDI, Pulcinelli Eni. As formas do silêncio - no movimento dos sentidos. Campinas: Editora da Unicamp, 2007.

PATROCÍNIO, Paulo Roberto Tonani do. A voz da periferia e a função do intelectual. Darandina Revista eletrônica, n. 3, p. 1-14, 2010. 
PELÚCIO, Larissa. Subalterno quem, cara pálida?: apontamentos às margens sobre póscolonialismos, feminismos e estudos queer. Contemporânea - Revista de Sociologia da UFSCar. n. 2, v. 2, p. 395-418, 2012.

PRADO, Marco Aurélio Máximo. Da Mobilidade social à constituição da identidade política: reflexões em torno dos aspectos psicossociais das ações coletivas. Psicologia em Revista, Belo Horizonte, n. 8, n. 11, p. 59-71, 2002.

ROIO, Marcos Del. Gramsci e a emancipação do subalterno. Revista de Sociologia Política, Curitiba, v. 29, p. 63-78, 2007.

SIMIONATTO, Ivete. Política, cultura e hegemonia: as classes subalternas em questão. In: Seminário Internacional Gramsci e os Movimentos Populares, Niterói, 2010, p. 35-45. Disponível em: http://www.nufipeuff.org/seminario gramsci e os movimentos populares/trabalhos/Ivete Si mionatto.pdf. Acesso em 22 de junho de 2015.

SPIVAK, Gayatri Chakravorty. Quem reivindica alteridade?. In: HOLLANDA, Heloisa Buarque de (Org.). Tendências e impasses: o feminismo como crítica da cultura. Rio de Janeiro: Rocco, p. 187-205, 1994.

- A Critique of Postcolonial Reason: Towards a History of the Vanishing Present. Cambridge: Harevard University Press, 1999.

Pode o subalterno falar?. Tradução de Sandra R. Goulart Almeida; Marcos Feitosa; André Feitosa. Belo Horizonte: Editora UFMG, 2010.

Critica del aragione postcoloniale. Roma: Meltemi, 2004.

VERÇOZA, Lúcio Vasconcellos de. Sobre a possibilidade ou impossibilidade de fala do subalterno e o papel do intelectual: notas acerca da reflexão de Spivak. In: Anais do III Seminário do PPGS UFSCar: Sociologia em movimento: novos olhares, novas perspectivas, São Carlos, 2012, p. 1-10. Disponível em: http://iiiseminarioppgsufscar.files.wordpress.com/2012/04/vercoza lc3bacio.pdf. Acesso em 22 de junho de 2015.

[Recebido em fevereiro de 2015 e aceito para publicação em maio de 2015]

\section{The locus of enunciation of the subaltern subject: speech and silecing}

Abstract: This paper investigates the speech / silence of the subjects, aiming to establish a discussion around the complex debate about the locus of enunciation of subaltern subject in contemporary social life, especially in the scientific field. The contributions of theoretical Gayatri Chakravorty Spivak (2010) in the text "Can the subaltern speak?" were taken as the focus of this paper in which the author states that subordinates are those who do not participate, or participate in a very limited way, by being dumb subjects for the cultural imperialism and the epistemological violence. There is not consensus on the propositive way or the resignation over the Spivak's work (2010). Numerous criticisms are made to her intellectual thought. On the one hand some people will name the propositions of Gayatri as a theoretical who not propose any output from the inferiority condition of the subalterns, on the other people will point that she takes a firm and courageous stance by stating that the 
responsibility for fighting against the subordination is a role of intellectuals. The central point of this essay is the searching for frameworks, textual, social and policies structures that can encourage the emergence of voices that were silenced by imperialist political forces. Therefore it took as theoretical support the Subaltern South-Asian Studies and Postcolonial asking about these new subjects of scientific literature and its enunciation. This theoretical field is presented as an important contribution to the scientific field therefore it brings the "other" to the scene, the not speaker, the muted, which has always been the place of subject in science and, rarely, the subject of science.

Keywords: Subordination. Enuciation. Subaltern. Subaltern Studies. 